\title{
Preparation of Starch-Based Biodegradable Film and the Application in Agriculture
}

\author{
Lei Xu ${ }^{1}$, Xizhi Jiang ${ }^{1}$, Yongfu Zhao ${ }^{1} \&$ Liru Xia $^{1}$ \\ ${ }^{1}$ Institute of Agricultural Facilities and Equipments, Jiangsu Academy of Agricultural Sciences, Nanjing, China \\ Correspondence: Lei Xu, Institute of Agricultural Facilities and Equipments, Jiangsu Academy of Agricultural \\ Sciences, Nanjing 210014, China. E-mail: 410970661@qq.com
}

Received: December 2, 2016

Accepted: January 22, $2017 \quad$ Online Published: February 15, 2017

doi:10.5539/jas.v9n3p1

URL: http://dx.doi.org/10.5539/jas.v9n3p1

\begin{abstract}
A starch-based biodegradable film was prepared in this paper, and the properties of the film were discussed. The film was prepared with polyethylene grafted and blended by epichlorohydrin modified-corn starch, linear low density polyethylene, low density polyethylene and maleic anhydride. Epoxy soybean oil was served as plasticizer and a small amout of ethylene propylene diene monomer was used as compatibilizer. $0.012 \mathrm{~mm}$ thickness degradable films were prepared with various blow molding methods. FTIR was used to characterize the modified starch and SEM was used to observe the morphology of the film before and after the modification. The results showed that the film could maintain an excellent performance on mechanical properties and degradation until the content of modified starch increased to $70 \%$ and have a good future in agricultural application.
\end{abstract}

Keywords: corn-starch, epoxy soybean oil, agriculture

\section{Introduction}

In light of the global concern for the accumulation of waste, biodegradable materials were extensively investigated, in order to partially replace petroleum-based plastics (Averous \& Boquillon, 2004; Bertuzzi, Armada, \& Gottifredi, 2007; Buléon, Véronèse, \& Putaux, 2007). Among the many polymers used to develop biodegradable films, starch has been focus of investigations because it is a natural polymer from renewable resources, abundant and low cost, that is capable of forming continuous thermoplastic materials (Choi \& Kerr, 2003; Famá, Bittante, Sobral, Goyanes, \& Gerschenson, 2010; Famá, Ganan Rojo, Bernal, \& Goyanes, 2012; Farhat, Blanshard, \& Mitchell, 2000). High-amylose starches possess more advantages than low-amylose ones and the films prepared from high-amylose starches have better mechanical strength and gas barrier properties (Gaudín, Lourdin, Le Botlan, Ilari, \& Colonna, 1999; Gennadios, Weller, \& Gooding, 1994; Angellier, Choisnard, \& Molina-Boisseau, 2004). However, like other hydrocolloids, starch films exhibit several drawbacks when compared to plastic polymers, such as their hydrophilic character and poor mechanical properties, which can be improved by blending with other compounds in the film (Angellier, Molina-Boisseau, Lebrun, \& Dufresne, 2005; Briassoulis, 2004; Carmen, Müllera, João, \& Fabio, 2011; De la Caba, Pena, Ciannamea, Stefani, Mondragon, \& Ruseckaite, 2012).

\section{Experiment}

\subsection{Material}

LLDPE (DJM-1830), LDPE (DJM-1810), Yangzi Petrochemical Company; Maleic anhydride grafted polyethylene (Graft ratio 1.3\%), Nanjing Deba polymer materials Co. Ltd.; EPDM (MITSUI EPT 3045), Mitsui Chemicals Inc; Epoxy soybean oil, Shandong Jian Feng Chemical; Corn starch, Commercially available; Epoxy propane, Shanghai Ling Feng Chemical Reagent Co., Ltd.

\subsection{Synthesis and Characterization}

All the polymerizations were carried out under nitrogen atmosphere in a three-neck flask equipped with reflux condenser, mechanical stirrer, inlet for nitrogen gas and heated in water bath. In the first stage, $40 \% \mathrm{wt}$ starch emulsion and $\mathrm{NaCl}$ were stirred with a speed of $60 \mathrm{r} / \mathrm{min}$. And then adjust the $\mathrm{pH}$ value to 10 with $1 \mathrm{~mol} / \mathrm{L}$ $\mathrm{NaOH}$. And then cross-linked starch was obtained by a 3 hours reaction at $35{ }^{\circ} \mathrm{C}$ after the addition of epoxy propane. In the second stage, adjust the $\mathrm{pH}$ value to $6-6.8$ with $2 \%$ wt hydrochloric acid, and then filter the 
emulsion and dry the solid material for grinding to powder. In the third stage, heat the internal mixer to 140-150 ${ }^{\circ} \mathrm{C}$, and then mix the modified starch, EPDM, epoxy soybean oil, maleic anhydride grafted polyethylene, LLDPE, LDPE in order to improve the dispersion and compatibility of the starch. In the last film blowing stage, adjust the ratio of blowing, traction and wind speed to make maleic anhydride grafted polyethylene, LLDPE and LDPE crosslink in proper orientation. Fourier Transform Infrared (FTIR) spectra of crosslinked starch were recorded on a Prostar LC240 Infrared Spectrometer (USA). Mechanical properties of the film were tested in universal testing machine, the drawing speed is $200 \mathrm{~mm} / \mathrm{min}$. Degradation properties of the film were tested in the way of weight loss rate. Scanning electron microscope (SEM) of the film of different degradation stage was prepared.

\section{Results and Discussion}

\subsection{FT-IR Analysis}
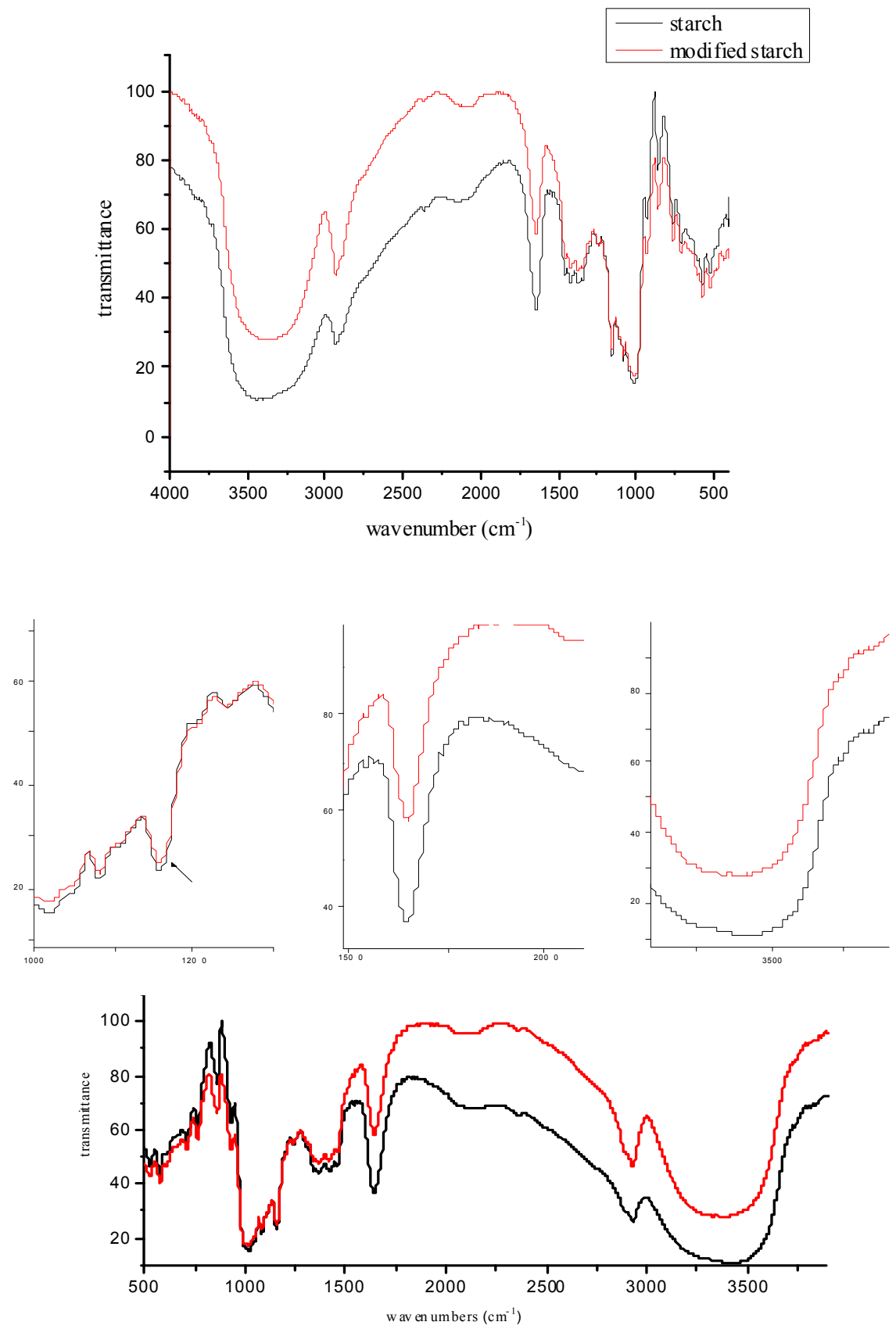

Figure 1. Infrared absorption spectroscopy of original starch and modified starch 
From Figure 1, the main infrared spectral bands of corn starch are $3438 \mathrm{~cm}^{-1}, 2903 \mathrm{~cm}^{-1}, 1645 \mathrm{~cm}^{-1}, 1420 \mathrm{~cm}^{-1}$, $1369 \mathrm{~cm}^{-1}, 1157 \mathrm{~cm}^{-1}, 1081 \mathrm{~cm}^{-1}, 1018 \mathrm{~cm}^{-1}, 931 \mathrm{~cm}^{-1}, 860 \mathrm{~cm}^{-1}, 764 \mathrm{~cm}^{-1}$. The chemical bands of starch and modified starch are basically the same. The stretching vibration of $-\mathrm{OH}$ in $3428 \mathrm{~cm}^{-1}$, intramolecular hydrogen bond in $1645 \mathrm{~cm}^{-1}$, and stretching vibration of C-O between starch and modified starch are different. In original starch, - $\mathrm{OH}$ bands in position 2,3,5 could stretch vibration, the curve presented gentle broad peaks due to the different position of $-\mathrm{OH}$ bands. But with the generation of cross linked bonds, stretching vibration peaks of -OH bands narrowed and the position of -OH band shifted from $3438 \mathrm{~cm}^{-1}$ to $3367 \mathrm{~cm}^{-1}$ because of the cross linked reaction which cause the kinds of $-\mathrm{OH}$ bands decreased. Peak at $1645 \mathrm{~cm}^{-1}$ weakened in modified starch because of the generation of cross linked bands and the replacement of hydrogen bond. Ether bond absorption peak in modified starch is stronger than common starch in $1157 \mathrm{~cm}^{-1}$ also because of the cross linked reaction. Peak at $1018 \mathrm{~cm}^{-1}$ could be used to determine the peak height of the starch molecules in the crystalline state and amorphous morphology of the mutual conversion.

\subsection{Analysis of Mechanical Properties}
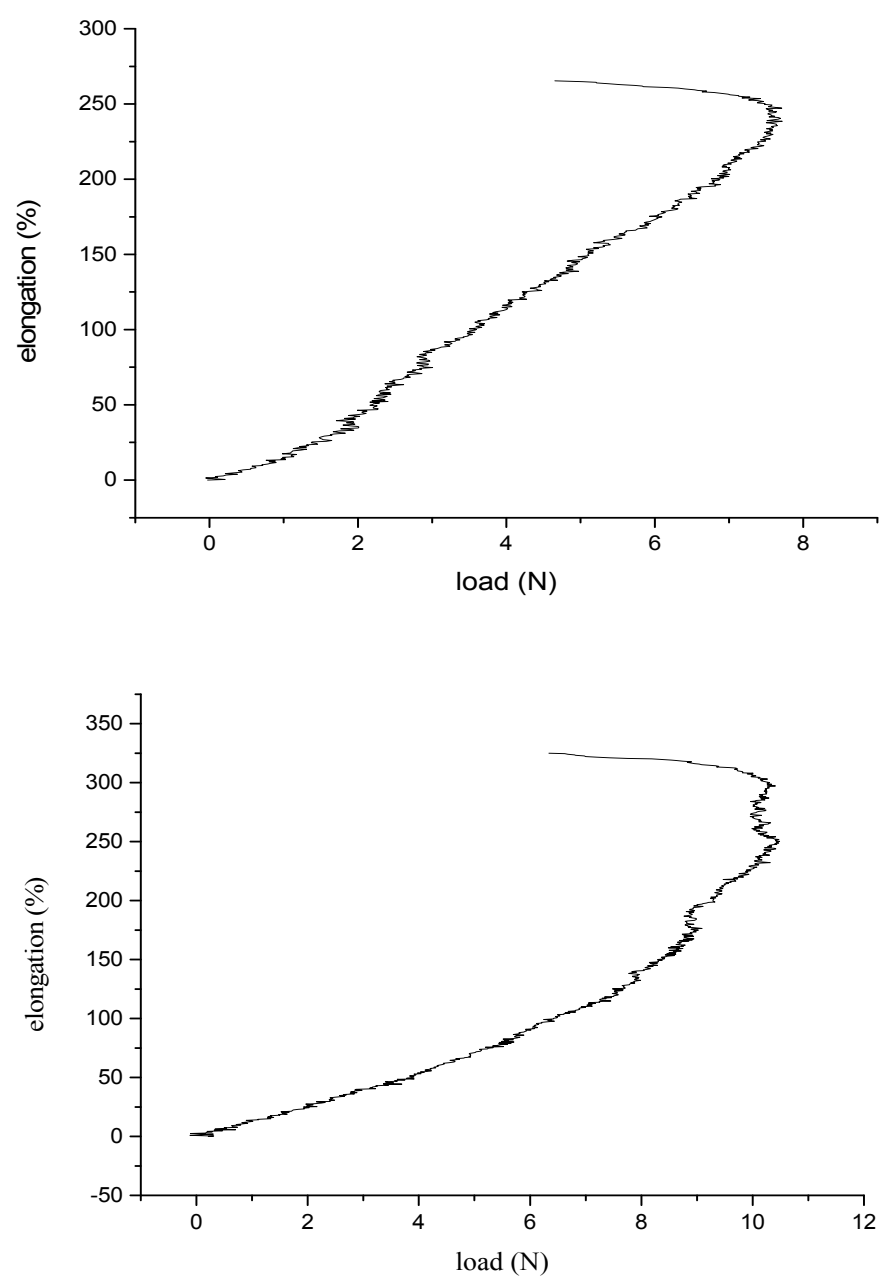

Figures 2 and 3. Curve of longitudinal tear and horizontal tear of $70 \%$ content starch film

The samples were handled according to GB/T 16578-1996. From Figures 2 and 3, the tearing curve showed that the elongation at break increased with the increase of load whether vertically or horizontally. This is because the addition of ethylene propylene rubber, the film have a good longitudinal and transverse tear performance.

\subsection{SEM Images}




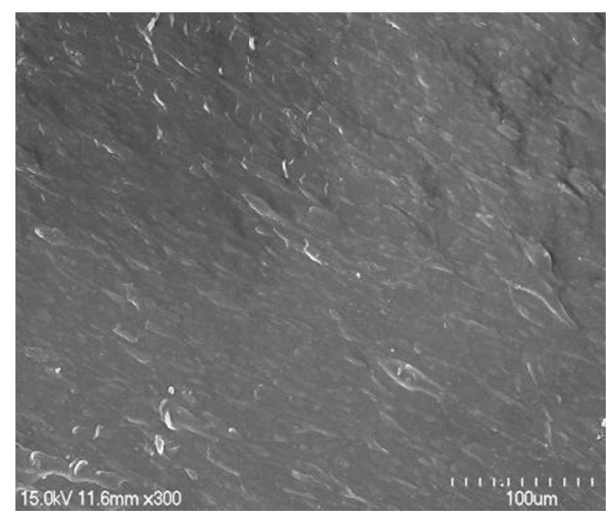

Figure 4. SEM picture of $40 \%$ starch content film

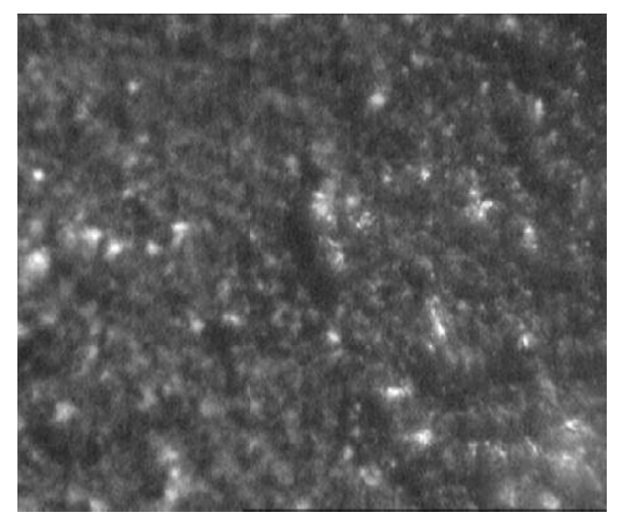

Figure 5. Magnification microscope of $70 \%$ starch content film

SEM images of starch-PE composite film were shown as Figures 4 and 5. PE and starch have good compatibility and present a continuous phase when the content of starch was $40 \%$ wt. This is because the addition of epoxy soybean oil and other elastic particles which could increase toughness of starch-PE composite and the starch more evenly dispersed in PE. In the other hand, the spherulite structure of the starch was destroyed due to the cross-linked phase, and the granular structure of starch disappeared after extrusion and plastic. So PE composite thin films have excellent mechanical properties although the content of starch increases to $70 \%$ wt. A small amount of starch granules as is shown in Figure 5. This is because the small amount of PE and the increased amount of starch.

\subsection{Analysis of Degradation Property}

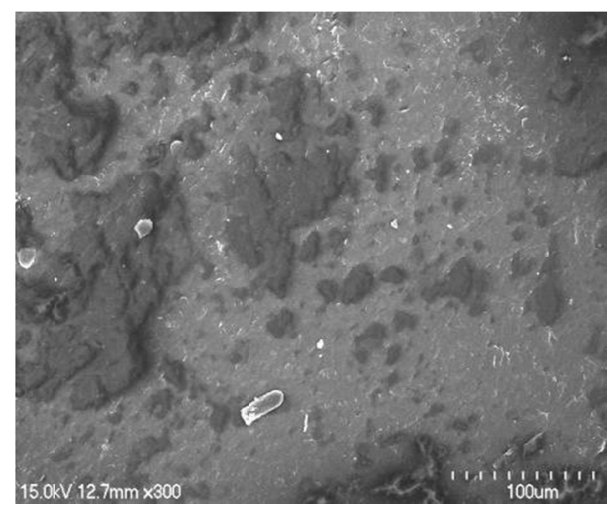

Figure 6. Weight loss percentage of $40 \%$ starch-PE film 


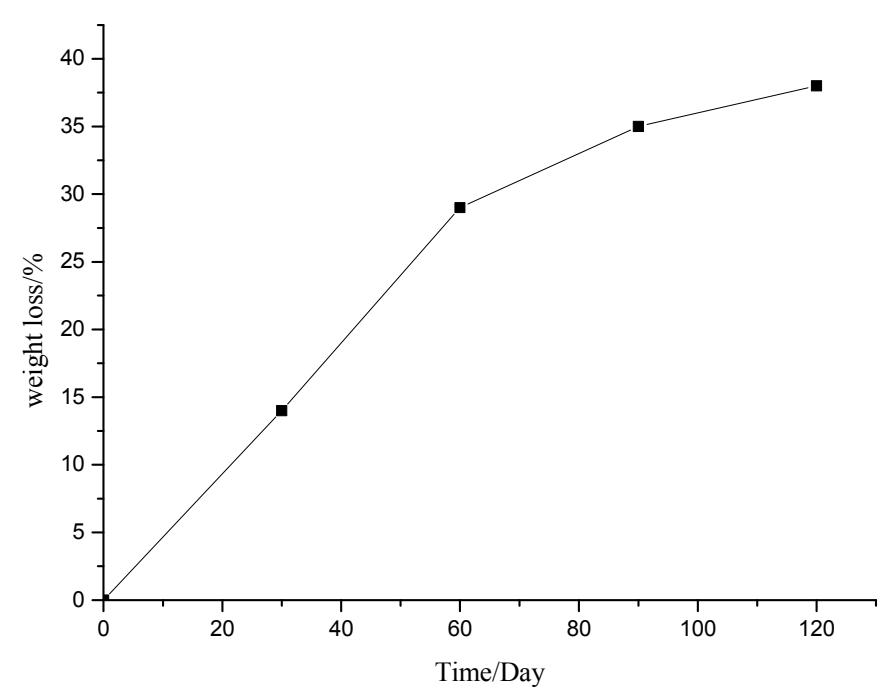

Figure 7. SEM of film after 120 day degradation

As is shown in Figures 6 and 7, the weight loss of $40 \%$ content starch-PE film was very obvious. Weight loss could reach 35\% after 90 days and reach 38\% after 120 days. From the SEM image in Figure 7, the film has degraded to small particles and could reduce the pollution of the environment.

\subsection{Agricultural Application of Starch Films}

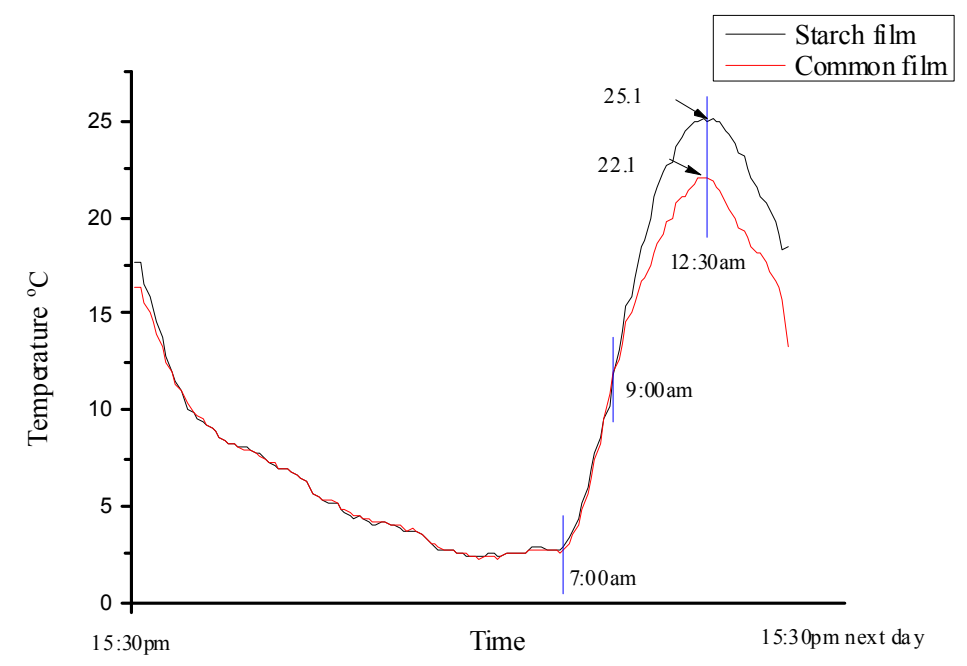

Figure 8. Comparison of temperature between starch film and common film

As is shown in Figure 8, data were collected from 15:30 pm of the first day to the same time of the following day. Temperature in starch film grew more considerably compared with common film after 9:00 am of the following day, and reached the peak at $25.1{ }^{\circ} \mathrm{C}$ at 12:30 am which was higher compared with common film.

\section{Conclusions}

A biodegradable starch film was prepared in this paper and the properties were characterized. The film was blown by PE and modified starch and the mechanical properties have increased with the addition of elastic particle. The starch film was used in agriculture and shows a better performance than common films. 


\section{Acknowledgements}

This work was financially supported by Independent Innovation of Agricultural Sciences in Jiangsu Province CX(15)1033-01.

\section{References}

Angellier, H., Choisnard, L., \& Molina-Boisseau, S. (2004). Optimization of the preparation of aqueous suspensions of waxy maize starch nanocrystals using a response surface methodology. Biomacromolecules, 5, 1545-1551. https://doi.org/10.1021/bm049914u

Angellier, H., Molina-Boisseau, S., Lebrun, L., \& Dufresne, A. (2005). Processing and structural properties of waxy maize starch nanocrystals reinforced natural rubber. Macromolecules, 38(9), 3783-3792. https://doi.org/10.1021/ma050054z

Averous, L., \& Boquillon, N. (2004). Biocomposites based on plasticized starch: Thermal and mechanical behaviours. Carbohydrate Polymers, 56(2), 111-122. https://doi.org/10.1016/j.carbpol.2003.11.015

Bertuzzi, M. A., Armada, M., \& Gottifredi, J. C. (2007). Physicochemical characterization of starch based films. Journal of Food Engineering, 82(1), 17-25. https://doi.org/10.1016/j.jfoodeng.2006.12.016

Briassoulis, D. (2004). An overview on the mechanical behavior of biodegradable agricultural films. Journal of Polymers and the Environment, 12, 65-81. https://doi.org/10.1023/B:JOOE.0000010052.86786.ef

Buléon, A., Véronèse, G., \& Putaux, J.-L. (2007). Self-association and crystallization of amylose. Australian Journal of Chemistry, 60(10), 706-718. https://doi.org/10.1071/CH07168

Carmen, M. O., Müllera, B., João, B. L., \& Fabio, Y. (2011). Effect of nanoclay incorporation method on mechanical and water vapor barrier properties of starch-based films. Industrial Crops and Products, 33, 605-610. https://doi.org/10.1016/j.indcrop.2010.12.021

Choi, S. G., \& Kerr, W. L. (2003). 1H NMR studies of molecular mobility in wheat starch. Food Research International, 36(4), 341-348. https://doi.org/10.1016/S0963-9969(02)00225-9

De la Caba, K., Pena, C., Ciannamea, E. M., Stefani, P. M., Mondragon, I., \& Ruseckaite, R. A. (2012). Characterization of soybean protein concentrate-stearic acid/palmitic acid blend edible films. Journal of Applied Polymer Science, 124(2012), 1796-1807. https://doi.org/10.1002/app.35188

Famá, L., Bittante, A. M. B. Q., Sobral, P. J. A., Goyanes, S., \& Gerschenson, L. N. (2010). Garlic powder and wheat bran as fillers: Their effect on thephysicochemical properties of edible biocomposites. Material Science and Engineering C, 30, 853-859. https://doi.org/10.1016/j.msec.2010.03.022

Famá, L., Ganan Rojo, P., Bernal, C., \& Goyanes, S. (2012). Biodegradable starch based nanocomposites with low water vapor permeability and high storage modulus. Carbohydrate Polymers, 87(3), 1989-1993. https://doi.org/10.1016/j.carbpol.2011.10.007

Farhat, I. A., Blanshard, J. M. V., \& Mitchell, J. R. (2000). The retrogradation of waxy maize starch extrudates: Effects of storage temperature and water content. Biopolymers, 53(5), 411-422. https://doi.org/10.1002/ (SICI)1097-0282(20000415)53:5\%3C411::AID-BIP5\%3E3.0.CO;2-M

Gaudín, S., Lourdin, D., Le Botlan, D., Ilari, J. L., \& Colonna, P. (1999). Plasticisation and mobility in starch-sorbitol films. Journal of Cereal Science, 29(3), 273-284. https://doi.org/10.1006/jcrs.1999.0236

Gennadios, A., Weller, C. L., \& Gooding, C. H. (1994). Measurement errors in water vapor permeability of highly permeable, hydrophilic edible films. Journal of Food Engineering, 21(4), 395-409. https://doi.org/10.1016/0260-8774(94)90062-0

\section{Copyrights}

Copyright for this article is retained by the author(s), with first publication rights granted to the journal.

This is an open-access article distributed under the terms and conditions of the Creative Commons Attribution license (http://creativecommons.org/licenses/by/4.0/). 